\title{
Comparative Effectiveness of the Recommended Instructional Strategies on Students' Environmental Knowledge in Social Studies in Osun State Middle Schools
}

\author{
Dr. A. J. Obadiora
}

Department of Arts and Social Science Education, Faculty of Education, Obafemi Awololowo University Ile-Ife

\author{
Doi:10.5901/jesr.2016.v6n3p45
}

\begin{abstract}
This study compared the effectiveness of e-learning, collaborative and field trip instructional strategies on students' environmental knowledge in Social Studies in Osun State middle schools. The sample consisted of 243 middle school one (MSI) students. Four public schools were randomly selected for the study. From each of the four schools, one intact MS1 class was randomly assigned to either e-learning, collaborative, field trip or conventional group. One instrument was used for this study. Data collected were subjected to analysis of covariance (ANCOVA). The results showed that there was a significant difference in the effectiveness of e-learning, collaborative, field trip and conventional strategies on students' environmental knowledge in Social Studies ( $F=171.735)$ in favour of e-learning, field trip and collaborative respectively $p=0.000$. The results also indicated no significant interaction effect of each strategy and gender $(F=0.447, p=0.816)$. The results as well showed significant interaction effect across strategies and gender $(F=187.829)$ in favour of e-learning, field trip and collaborative $p=$ 0.000. Based on the findings of this study it was concluded that the three learner centre strategies are effective in enhancing students' acquisition of adequate knowledge about the environment through Social Studies education whereas gender has no significant effect on the students' performance.
\end{abstract}

Keywords: Instructional Strategies, Environmental Knowledge, Social Studies

\section{Introduction}

Environmental degradation has become contemporary national and international issue; this is because the combined effects of series of wars, industrial revolution, increase in population and poverty in different parts of the world have led to the present situation of the earth environment. Hobish (1999), and Giberson (2011) believed that the only planet that bears lives presently is earth because among the other planets only the earth stands at the right distance from the sun to have temperatures that are suitable for life to exist. The same earth man has sacrificed for economical, social and scientific advancement. Almost all things that can make life adaptable on earth have been polluted or destroyed.

In Nigeria, poverty, unemployment, increase in population, industrial activities and improper disposition of domestic and industrial wastes among others have resulted to over utilization and improper management of the environment. It could not be ascertained that several environmental acts and agencies established in Nigeria possess functional ability to address series of environmental challenges in Nigeria or could help people to acquire genuine knowledge/behaviour about the environment. Omofomwan (2008) argued that with all the environmental laws and agencies in Nigeria, environmental degradation is growing worse everyday.

It has been realized that Nigerian children and youths who play major roles in environmental degradation lack adequate knowledge about the environment and the damages being done to it through various activities. Ehindero (2006) agreed that average Nigerian lack awareness of gradual decline in the quality of the environment. They hold on to different incorrect primitive points of view that are capable of causing environmental degradation, illness and disasters. For instance, some people believe that there is no level of exploitation of the natural resources can lead to the destruction/extinction of the resources, some claim that flooding is caused by the annoyance of marine spirits not by human's activities, while some do say that the dirt of flowing water cannot kill human being "Egbin omi to nsan kii paniyan"; to mention a few. This type of belief encourages people to over exploit and gradually diminishes their local natural environment without replacement.

Improper management of the environment in Nigeria is evident in the way people, both male and female, interact and use the environment. For instance, people and industries dispose domestic and industrial waste indiscriminately into the water way, nearest river, lake, street, road side, or uncompleted building without minding the adverse consequences on people's health. Such indiscriminate dumping often pollutes the air, soil and water, block water paths and causes serious illness and flood disaster in different parts of the country. On several occasions, brooks, rivers, lakes, streams, trenches, roads and open spaces in Nigeria were despoiled and contaminated by pollution. In some villages, people 
defecate inside the river/stream or wash dirty clothes inside the stream (for example the dry cleaners) and the same water is used for their domestic consumption.

Often, people break into the forest and engaged themselves in indiscriminate felling of trees and poaching of wild animals without sparing the young ones. These negative practices are learnt and exhibit by children and youths from parents, guardians or other adults. Today, Nigerian children and youths being the most active and largest group of the population play major roles in environmental degradation in the society. Ehindero (2006) said that it is upon the will of individuals, who together make up the general public that the environment can be protected. Then, how can the youth be aware and willingly get involved in protecting and conserving the environment for sustainable development. While the law is important, education is the key to eliminate environmental and social ills. Education is virtue, it makes up the qualities of a person and brings about the value of a society. It is believed that education could be very functional when it comes to addressing societal issues. It is not necessary to force discipline on people or force people to do the right thing at all times, they must be enlightened to understand why they have to do things right. Education is vital in producing behavioural change and it is essential to the success of environmental protection campaign.

The concern of the Nigerian government and elites to design the country's educational goals in terms of their relevancies to the needs of the individuals and the society among other variables led to the introduction of subject like Social Studies into the Nigerian educational programme. Social Studies is a systematic study of human interaction with the environment. Social Studies has become one of the strategic educational tools that Nigerian governments embrace to provide adequate information for all round development of her children and youth and to address some societal issues. Social Studies is embraced to enable Nigerian students understand their relationships with their physical, cultural, social and economic environments and to understand those of other human communities (Makinde, 1979). Through Social Studies, the child develops consciousness of the nature of the society, a sense of stewardship concerning the land as well as commitment to the practice of sustainable development.

Scholars such as Edinyang, Eneji, Tijani and Dunnamah (2013) believed that there is a mutual link between Social Studies and environmental education and that the effective utilization of such relationship will go along way with the realization of a worthwhile environment in Nigeria. Jekayinfa and Yusuf (2004) had empirically confirmed that professional teachers at primary and secondary/middle school levels of education in Nigeria perceived Social Studies as a subject most suitable for the infusion of environmental education at primary and secondary/middle school levels of education because Social Studies emphasizes the interaction of humanbeing with the environment. Social Studies can be used to promote environmental awareness, proper management and the utilization of environment for a sustainable development.

Effective teaching leads to the expected relative change in behaviour. The successful implementation of Social Studies curriculum in the middle school (MS) focuses on meeting the needs and solving problems arising from human's interaction in the society. If there is a need for the Nigerian students to gain the required awareness and knowledge that will enable them to effectively deal with contemporary negative environmental practices through Social Studies, the subject must be effectively taught. Ajiboye and Ajitoni (2007) recommended that any method where necessary experience is provided for the students to interact with the environment could be effective in promoting knowledge and change students' attitude toward the environment.

Nigerian Educational Research and Development Council (NERDC) as a body in charge of secondary school curriculum development has recommended some instructional strategies to implement environmental content of the Social Studies curriculum these strategies are field trip, e-learning, collaborative, and discussion strategies (NERDC, 2007). The strategies have been suggested to enable students to interact with the environment and participate actively in teaching-learning process. Scholars have confirmed that e-learning (Babalola 2007, Atta, Jamil, Ali, Ayaz \& Bashir 2013), collaborative learning (Dillenbourg 1999, Terenzini, Cabrera, Colbeck, Parente \& Bjorklund 2001, Hillen 2006), field-trip (Rickinson, Dillon, Teamey, Morris, Choi, Sanders \& Benefield 2004, Prokop, Tuncer, \& Kvasnicak 2007, Ajaja 2010) among others are learner centred strategies that provide opportunity for the learners to interact and have experience with the environment. Following this, it is pertinent to compare the effectiveness of e-learning, collaborative learning and fieldtrip strategies in enhancing acquisition of adequate knowledge about the environment through Social Studies with a view to solving the contemporary environmental problems in the Nigerian society.

\section{Objective}

This study intend to:

a. examine the effectiveness of e-learning, collaborative, field trip and conventional instructional strategies on 
students' academic performance in Social Studies environmental education in Osun State middle schools:

b. investigate the interaction effect of the strategies and gender on students' academic performance in Social Studies environmental education in Osun State middle schools

\section{Hypotheses}

From the objectives of this study, the following null hypotheses were generated.

Ho1: There is no significant effectiveness of e-learning, collaborative, field trip and conventional instructional strategies on students' academic performance in Social Studies environmental education in Osun State middle schools.

$\mathrm{Ho}_{2 \mathrm{a}}$ : There is no significant interaction effect of the four instructional strategies and gender on students' academic performance in Social Studies environmental education in Osun State middle schools.

Ho $_{2 b}$ : There is no significant interaction effect across the four strategies and gender on students' academic performance in Social Studies environmental education in Osun State middle schools.

\section{Theoretical Framework}

This study is based on constructive learning theory. Constructivism is basically a theory concerned about observation and scientific study of how people learn. It says that people construct their own understanding and knowledge of the world, through experiencing things and reflecting on those experiences (McAndrew, 2012). Lisa (2008) identified constructivism as a type of learning theory that explains human learning as an active attempt to construct meaning in the world around them. Sullo (2012) in his own opinion elucidated constructivism as a philosophy of learning founded on the premise that, by reflecting on one's experiences, individual construct understanding of the world he/she lives in. Everybody generates personal rules and mental models which he/she uses to make sense of his/her experiences. Therefore learning is simply the process of adjusting mental models to accommodate new experiences.

Central to the principle of constructivism is the belief that learning is an active process and that the learner is at the middle of the learning process. Constructivists therefore, advocate for learners' active participation in teaching-learning process based on the belief that information may be imposed, but understanding cannot because it must come from within (Tam, 2000). Constructivists are concerned with how learners will be involved and be connected with the outcomes of the lesson. The essential care of constructivism is that learners should construct their own knowledge and interpret reality in the context of their experiences (Jonassen, 1991; Fosnot, 1996; Steffe \& Gale, 1995). In one sum, constructivism believes that the role of the teacher is to guide the learners to construct personal meaning.

In line with the constructive learning theories, this study focuses on the use of three instructional strategies (elearning, collaborative learning and field trip instructional strategies) that give room for active participation of students in the teaching-learning process. The strategies allow students to handle lesson activities with the teacher as a guide to help along the way, gives students opportunity to handle teaching-learning activities, helps develop right ideas and interpret situations correctly based on individual views, participation interaction and experiences. It also enables students to develop internal picture or illustration of knowledge and learn better by trying to make sense of something independently under the guidance of the teacher.

\section{Methodology}

The study employed the non-equivalent pretest-posttest control group design. This is a type of quasi-experimental design that uses the groups as they are already organized into classes that is intact class (Ary, Jacobs, Razavieh and Sorensen, 2006). The study population comprised middle school one (MSI) students of Osun State. The sample consisted of 243 MSI students. Four public middle schools were selected in Osun State. From each of the four schools, one intact MSI class was randomly selected making the total of four intact classes. The four intact classes were randomly assigned to experimental and control groups. There were three experimental groups and one control group. The experimental and control groups were given a pre-test on the subject matter. They were also taught the same environmental content (i:e meaning and features of physical environment, utilization of environment, environmental problems and their effects, and solution to environmental problems) using different teaching method that is e-learning, collaborative learning, field trip and teacher expository methods, after which they were given a post test on the subject matter.

One instruments was used for this study namely Social Studies Environmental Education Test (SSEET). SSEET was used to collect data on the knowledge of the students about the environment. The SSEET has two sections, section 
A contained the instruction and seven items that have to do with personal data of the respondents. Section B consisted of a multiple choice test of 20 items on environmental issues. The instructional packages and materials used for the study include Video CD documentary that describes and discusses environmental issues, this was used as instructional package for the e-learning groups. A-3 page worksheet was used as instructional package for the fiield trip groups to guide the students on how to write note while on the trip. The environmental contents aforementioned were converted into 10 topics which were given to the collaborative groups as project. No instructional package was prepared for the control group.

The study was carried out in eight weeks and data collection was in three phases. In the first phase, the first week was used to meet and strategize with the research assistants on how to carry out the exercise. The second week was used for the administration of the research instrument on the sample students as the pre test. Administration of the research instrument followed the same format for all the groups, all respondents answered the same objective test. The second phase (the treatment stage) began in the third week of the study. During this period, some of the co-opted teachers of the selected schools taught the students the same environmental education concepts with different instructional strategies. This was done in four weeks because of the dictate of the schools' time table and the number of the schools involved in the study. Each member of the first experimental group (group A) was given electronic package which contained environmental documentary to study for one week after which the content of the package was discussed in the classroom.

The co-opted school teachers of the second experimental group (group B) within two weeks prepared and carried out a field trip with the experimental group in the company of the researcher to relevant places within the community to study the environment and contemporary environmental issues. Each of the students in this group was given a note/record guide to summarize his/her view of the trip upon which there was a classroom discussion. The third experimental group (group C) was divided into small groups to carry out a project on environmental issues. Each group was provided different topics to study for the period of two weeks. At the conclusion of the project individual group discussed her findings with the whole class. The control group (group D) was taught with the conventional teacher exposition method. The third phase of the study started at the beginning of the seventh week. During this period the research instruments was administered on the same group of students as the post-test in the same way it was done in the pretest. This also took place in two weeks. The scoring was done by the researcher and the research assistants.

\section{Results}

The results of the study are presented according to the hypotheses generated and tested.

Ho1: There is no significant effectiveness of e-learning, collaborative, field trip and conventional instructional strategies on student's academic performance in Social Studies in Osun State middle schools.

The scores of the students in the experimental and control groups obtained with the use of SSEET were subjected to Analysis of Covariance (ANCOVA) to determine whether the hypothesis should be rejected or not. This was tested at 0.05 level of significance. The essence of this hypothesis is to determine the effect of each strategy on students' performance as well as compare the effects across the strategies by examining the difference between pre and post test scores of students exposed to each of the strategies and the post test scores across the four strategies. The results are presented in table 1.

Table 1: ANCOVA Tests of Between-Subjects Effects of the Four Instructional Strategies on the Students' Academic Performance

Tests of Between-Subjects Effects

Dependent Variable: Test Result

\begin{tabular}{|l|c|c|c|c|c|}
\hline Source & Type III Sum of Squares & df & Mean Square & F & Sig. \\
\hline Corrected Model & $6251.013 \mathrm{a}$ & 7 & 893.002 & 171.735 & .000 \\
Intercept & 44426.904 & 1 & 44426.904 & 8543.818 & .000 \\
Strategies & 6251.013 & 7 & 893.002 & 171.735 & .000 \\
Error & 2402.349 & 462 & 5.200 & & \\
Total & 53284.000 & 470 & & & \\
Corrected Total & 8653.362 & 469 & & & \\
\hline
\end{tabular}

a. $\mathrm{R}$ Squared $=.722$ (Adjusted R Squared $=.718$ ) 
The summary of ANCOVA of student's scores in the experimental and the control groups in table 1 showed that there is a significant effectiveness of e-learning, collaborative, field trip and conventional instructional strategies on students' performance with $F=171.735$ at $p<0.05$. The unadjusted deviation $=.722$ and the adjusted deviation $=.718$. Therefore, this aspect of the hypothesis is rejected. A post hoc analysis was also conducted to establish the direction of interaction effect observed so far. The summary of this analysis is presented in table 2.

Table 2: Scheffe Multiple Comparisons of Posttest Results

\begin{tabular}{|l|l|c|c|c|c|c|}
\hline \multirow{2}{*}{ (I) All Methods } & \multirow{2}{*}{ (J) All Methods } & \multirow{2}{*}{ Mean Difference (I-J) } & Std. Error & Sig. & \multicolumn{2}{c|}{ 95\% Confidence Interval } \\
\hline \multirow{3}{*}{ e-Learning Post Test } & & & Lower Bound & Upper Bound \\
\cline { 2 - 7 } & Collaborative Post Test & $6.5111^{*}$ & .46027 & .000 & 4.7763 & 8.2459 \\
\cline { 2 - 7 } & Field Trip Post Test & $5.6774^{*}$ & .42446 & .000 & 4.0776 & 7.2772 \\
\cline { 2 - 7 } Collaborative Post Test & Conventional Post Test & $8.2568^{*}$ & .40812 & .000 & 6.7185 & 9.7950 \\
\cline { 2 - 7 } & e-Learning Post Test & $-6.5111^{*}$ & .46027 & .000 & -8.2459 & -4.7763 \\
\cline { 2 - 7 } & Field Trip Post Test & -.8337 & .44657 & .836 & -2.5168 & .8494 \\
\hline \multirow{3}{*}{ Field Trip Post Test } & Conventional Post Test & $1.7456^{*}$ & .43107 & .023 & .1209 & 3.3704 \\
\cline { 2 - 7 } & e-Learning Post Test & $-5.6774^{*}$ & .42446 & .000 & -7.2772 & -4.0776 \\
\cline { 2 - 7 } & Collaborative Post Test & .8337 & .44657 & .836 & -.8494 & 2.5168 \\
\cline { 2 - 7 } Conventional Post Test & Conventional Post Test & $2.5793^{*}$ & .39260 & .000 & 1.0996 & 4.0591 \\
\cline { 2 - 7 } & e-Learning Post Test & $-8.2568^{*}$ & .40812 & .000 & -9.7950 & -6.7185 \\
\cline { 2 - 7 } & Collaborative Post Test & $-1.7456^{*}$ & .43107 & .023 & -3.3704 & -.1209 \\
\cline { 2 - 7 } & Field Trip Post Test & $-2.5793^{*}$ & .39260 & .000 & -4.0591 & -1.0996 \\
\hline
\end{tabular}

From table 2 the Scheffe multiple comparison of the posttest results showed the direction of the significant effectiveness of the strategies as follows e-learning (mean difference $=6.51,5.68$, and 8.26), field trip (mean difference $=-5.68,0.83$ and 2.58), collaborative (mean difference $=-6.51,-0.83$ and 1.75) and conventional strategies (mean difference $=-8.26$, 2.58 and-1.75). The results indicated that e-learning strategy is the most effective, follow by field trip, collaborative and conventional strategies.

Hoza: There is no significant interaction effect of the four instructional strategies and gender on students' academic performance in Social Studies environmental education in Osun State middle schools.

The scores of the male and female students in the experimental and control groups obtained with the use of SSEET were subjected to Analysis of Covariance (ANCOVA) to determine whether the hypothesis should be rejected or not. This was tested at 0.05 level of significance. The essence of this hypothesis is to determine the interaction effect of each strategy and gender on students' knowledge about the environment by examining the post test score of male and female students in each of the four strategies. The results are presented in table 3.

Table 3: ANCOVA Tests of Between-Subjects Interaction Effects of the Four Instructional Strategies and Gender on the Academic Performance of the Students

\begin{tabular}{|llccccr|}
\hline \multicolumn{7}{|c|}{ Tests of Between-Subjects Effects } \\
\hline \multicolumn{7}{|c|}{ Dependent Variable: Test Result } \\
Source & Type III Sum of Squares & df & Mean Square & F & Sig. \\
Intercept & Hypothesis & 42649.550 & 1 & 42649.550 & 37.664 .002 \\
& Error & 5653.807 & 4.993 & $1132.363^{\mathrm{a}}$ & \\
Each Sttategy and Gender & Hypothesis & 11.687 & 5 & 2.337 & 0.447 & .816 \\
& Error & 2390.662 & 457 & $5.231^{\mathrm{b}}$ & & \\
\hline
\end{tabular}

The results in table 3 showed that no significant interaction effect exist with gender in each of the strategy with $F=0.45$ at $p>0.05$. Therefore, this hypothesis is not rejected. A statistical description of interaction effect of the instructional strategies and gender was conducted for each of the strategy. The summary of this analysis is presented in table 4. 
Table 4: Statistical Description of the Interaction Effect of the Instructional Strategies and Gender on the Academic Performance of the Students

Descriptive Statistics
\begin{tabular}{|ll|c|c|c|} 
Dependent Variable: Test Result & All Methods & Mean & Std. Deviation & N \\
\hline Gender & e-Learning Pre-Test & 7.6765 & 2.01089 & 34 \\
\hline \multirow{2}{*}{ Male e-Learning } & e-Learning Post Test & 18.0882 & 1.92854 & 34 \\
& e-Learning Pre-Test & 6.9500 & 2.03845 & 20 \\
Female e-Learning & e-Learning Post Test & 17.8500 & 1.89945 & 20 \\
& Collaborative Pre-Test & 6.8077 & 2.62327 & 26 \\
Male Collaborative & Collaborative Post Test & 11.5385 & 2.83169 & 26 \\
& Collaborative Pre-Test & 7.3158 & 2.35826 & 19 \\
Female Collaborative & Collaborative Post Test & 11.4211 & 2.71448 & 19 \\
& Field Trip Pre-Test & 6.4615 & 2.21325 & 26 \\
Male Field Trip & Field Trip Post Test & 12.3846 & 2.33370 & 26 \\
& Field Trip Pre-Test & 6.6944 & 2.50507 & 36 \\
Female Field Trip & Field Trip Post Test & 12.2778 & 2.13289 & 36 \\
& Conventional Pre-Test & 6.2143 & 2.21454 & 42 \\
Male Conventional & Conventional Post Test & 9.7143 & 1.96662 & 42 \\
& Conventional Pre-Test & 6.9677 & 2.56234 & 31 \\
Female Conventional & Conventional Post Test & 9.6774 & 2.31498 & 31 \\
&
\end{tabular}

Table 4 showed the direction of the interaction effect of the instructional strategies and gender on students' posttest results as follows e-leaning strategy male posttest $=18.09$, female posttest $=17.85$, field trip strategy male posttest $=12.38$, female posttest $=12.28$, collaborative male posttest $=11.54$, female posttest $=11.42$ and conventional strategy male posttest $=9.71$, female posttest $=9.68$. The mean difference observed of the performance of male and female in each instructional strategy in this study is $<1$. These results indicate that gender has little or no influence on the student performance.

Ho2b: There is no significant interaction effect across the four strategies and gender on students' academic performance in Social Studies environmental education in Osun State middle schools.

The scores of the male and female students in the experimental and control groups obtained with the use of SSEET were subjected to Analysis of Covariance (ANCOVA) to determine whether the hypothesis should be rejected or not. This was tested at 0.05 level of significance. The essence of this hypothesis is to determine the interaction effect of the four strategies and gender on students' knowledge about the environment by comparing the effects across the strategies. The results are presented in table 5 .

Table 5: ANCOVA Tests of Between-Subjects Interaction Effects Across the Four Instructional Strategies and Gender on the Academic Performance of the Students

Tests of Between-Subjects Effects

Dependent Variable: Test Result

\begin{tabular}{|ll|c|c|c|c|c|}
\hline Source & & Type III Sum of Squares & df & Mean Square & F & Sig. \\
\hline \multirow{2}{*}{ Intercept } & Hypothesis & 42649.550 & 1 & 42649.550 & 37.664 & .002 \\
& Error & 5653.807 & 4.993 & $1132.363^{\mathrm{a}}$ & & \\
& Hypothesis & 4912.873 & 5 & 982.575 & 187.829 & .000 \\
\multirow{2}{*}{ Across Strategies and Gender } & Error & 2390.662 & 457 & $5.231^{\mathrm{b}}$ & & \\
& & &
\end{tabular}

a. 1.153 SS(All Strategies) - .153 SS(Error)

b. SS(Error)

The results in table 5 showed significant interaction effect of the strategies and gender observed across the strategies with $\mathrm{F}=187.829$ at $p<0.05$. Therefore, this hypothesis is rejected. A statistical description of interaction effect of the instructional strategies and gender was conducted for each of the strategy. The summary of this analysis is presented in table 4. The performance of male and female students in e-learning group (male posttest $=18.09$, female posttest $=$ 17.85 ) is significantly better than male and female students in the other groups (field trip, collaborative and conventional 
strategies). Likewise, the performance of male and female students in the field trip group (male posttest $=12.38$, female posttest $=12.28$ ) is better than those in the collaborative group (male posttest $=11.54$, female posttest $=11.42$ ) and significantly better than those in the conventional group (male posttest $=9.71$, female posttest $=9.68$ ). Lastly, the male and female students in collaborative group performed significantly better than those in the conventional group. These results showed that the existing significant interaction effect observed in hypothesis $2 b$ is influenced by the strategies not by gender.

\section{Discussion}

The results of this study showed that there is a significant effectiveness of e-learning, collaborative, field trip and conventional instructional strategies on students' academic performance in Social Studies environmental education in favour of e-learning, field trip and collaborative strategies respectively. This is in line with the study conducted by Russell and Waters (2010) on the "Instructional Methods for Teaching Social Studies: A Survey of What Middle School Students Like and Dislike about Social Studies Instruction" who concluded that middle school students want to use technology, go on field trips, work in cooperative learning groups, and be actively engaged with content. However, passive learning, such as lecture, note-taking, busy work, worksheets, and rote memorization is what students dislike about Social Studies.

Effectiveness of e-learning is empirically confirmed by the results of the study carried out by Babalola (2007) on the effectiveness of video as an instructional medium in teaching rural children agricultural and environmental sciences. The study revealed that the pupils taught with the video performed equally as well as those taught with real objects (Realia). While both groups performed significantly better than those taught without instructional medium. In the same vein, the findings of Atta, Jamil, Ali, Ayaz and Bashir (2013) on the comparative effectiveness of instructional technology regarding educational attainments of students at elementary level, showed that instructional strategy in which projected aids were used promote the educational attainments of students.

Several scholars have confirmed the findings of this study on field trip as an effective instructional strategy for instance, Prokop, Tuncer, and Kvasnicak (2007) conducted a one-day field trip for improving students' knowledge in ecology. Based on the results of the research conducted after the trip, students displayed a better understanding of ecology concepts like ecosystems and food webs. However, no similar pattern was observed for the control group who experienced only traditional Biology settings. The findings of Rickinson, Dillon, Teamey, Morris, Choi, Sanders and Benefield (2004) on a review of research on outdoor learning, also corroborate the results of this study that field trip strategy is an effective strategy of a great advantage to the learners. These scholars emphasized that evidence exists to indicate that fieldwork, properly conceived, adequately planned, well taught and effectively followed up, offers learners opportunities to develop their knowledge in ways that add value to their everyday experiences in the classroom.

The effectiveness of collaborative instructional strategy as discovered in this study is in line with the results of the investigation carried out by Terenzini, Cabrera, Colbeck, Parente and Bjorklund (2001) on Collaborative Learning vs. Lecture. The results indicated that collaborative method produce both statistically significant and substantially greater gains in student learning than those associated with more traditional instructional methods. The findings of this study on collaborative learning also agree with the work of Hillen (2006) where he investigated the effects of increased student discourse and cooperative learning on the students' ability to explain and understand Mathematics concepts and problem solving, as well as its effects on their use of vocabulary, written explanations and attitudes. It was discovered that increased student discourse and cooperative learning resulted in positive changes in students' attitudes about their ability to explain and understand Mathematics, as well as their actual ability to explain and understand Mathematics concepts.

The results of this study also agreed with the findings of Ojo (1992) and Yusuf (n. d) who revealed that gender has no effect on the performance of students when taught using either cooperative, competitive, individualistic or conventional instructional strategy.

\section{Conclusion}

This study concluded that all the three instructional strategies (e-learning, field trip and collaborative strategies) investigated in this study are effective in developing students' knowledge about the environment. Social Studies education can be used to promote students knowledge about the environment especially at the basic level of education where environmental education has not been introduced as a separate discipline. This study also concluded that education can be used to address some environmental issues. 


\section{Limitation}

This study was carried out among public middle school students in the urban area of Osun State. It was carried out on the environmental education in Social Studies curriculum.

\section{References}

Ajiboye, J. O. \& Ajitoni S.O., (2007). Exploring the use of participatory strategies in developing environmental attitude in Nigeria children implication for E.E teaching and learning. Pakistan Journal of Social Sciences. 2(1): 31-33.

Ary, D. Jacobs, L. C., Razavieh, A. \& Sorensen, C. (2006). Introduction to research in education. Canada: Vicki Night

Babalola, I. (2007). Effectiveness of video as an instructional medium in teaching rural children agricultural and environmental sciences Lagos State University, Nigeria. International Journal of Education and Development using Information and Communication Technology (IJEDICT), 2007, Vol. 3, Issue 3, pp. 105-114.

Badrul, H. K. (2004). The People-Process-Product Continuum in E-Learning: The E-Learning P3 Model Issue of Educational Technology, Volume 44, Number 5, Pages 33-40.

Myers, B. \& Jones, L. (2009). Effective Use of Field Trips in Educational Programming: A Three Stage Approach1 Agricultural Education and Communication Department, Florida Cooperative Extension Service, Institute of Food and Agricultural Sciences, University of Florida. http://edis.ifas.ufl.edu.

Dillenbourg, P. (1999) What do yuo mean by collaborative leraning?. In P. Dillenbourg (Ed) Collaborative-learning: Cognitive and Computational Approaches. (pp.1-19). Oxford: Elsevier

Douglason, G. O. (2004). An Analysis of Federal Government Expenditure in the Education Sector of Nigeria: Implication for National Development. Abraka: Department of Economic, Delta State University, Nigeria. Journal of Social Sciences Vol. 9 (2): pp.105110. E-mail: yomotor@yahoo.com.

Edinyang, S. D., Eneji, C. Ogar., Tijani, O. A. \& Dunnamah, A.Y., (2013). Environmental and Social Studies education: A collaborative approach towards building an environmentally friendly society. Educational Research Vol. 4(3) pp. 222-226, http://www.interes journals.org/ER

Ehindero O. J. (2006) Environmental education and sustainable development. Lagos: lantern books

Federal Ministry of Education (2007). 9 - Year basic education curriculum Social Studies for junior secondary 1-3. Abuja: Nigerian Educational Research and Development Council.

Fosnot, C. T., (1996). Constructivism: Theory, perspective, and practice. New York: Teachers College Press.

Giberson, K. W. (2012). The wonder of the universe: hints of God in our fine-tuned world. Downers Grove, III: InterVarsity Press, paperback. Retrieved on 29/04/2013 from http://bylogos.blogspot.com/2012/07/review-gibersons-wonder-of-universe.html.

Hillen, K. N., (2006). Discourse and Cooperative Learning in the Math Classroom. University of Nebraska - Lincoln: Summative Projects for MA Degree. Paper 10. http://digitalcommons.unl.edu/mathmidsummative/10 .

Hobish, M. K (1999). Earth Is a Planet, Too! Inhabited Worlds: It takes one to know one. National Space Society and Reston Communications. Retrieved on 21/05/2012 from The Astrobiology Web.

Jekayinfa, A. A. \& Yusuf, A. (2004). An investigation into student teachers' views on the introdution of environmental education into the Nigerian Social Studies curriculum Instituted Journal of Studies in Education 2(1),

Jonassen, D. H., (1991). Objectivism versus constructivism: do we need a new philosophical paradigm? Journal of Educational Research, 39 (3), 5-14.

Lisa Fritscher, (2008). Constructivism. About.com Guide Updated May 09, 2008 http://phobias.about.com/od/glossary/g/constructivdef. $\mathrm{htm}$.

Makinde, M. A. (1979). Integrated Social studies - A Handbook. on Social Studies for Teachers. Ibadan: University Press Ltd.

Atta, M. A., Jamil, A., Ali, U., Ayaz, M. \& Bashir, S. (2013) Comparative effectiveness of instructional technology regarding educational attainments of students at elementary level. Gomal University Journal of Research, 29(1). June 2013

Rickinson, M., Dillon, J., Teamey, k., Morris, M., Choi, M., Y., Sanders, D. \& Benefield, P. (2004) A review of Research on Outdoor Learning. National Foundation for Educational Research and King's College London.

McAndrew, A., (2012). Constructivism as a Paradigm for Teaching and Learning. Retrieved on 23/02/2013 from www.thirteen.org.

Meryfield, M. M. (1988). The African Social Studies programme: An effort to improve curriculum and instruction across 17 nations. Indiana: ERIC Clearinghouse.

Ojo, M. O (1992). The differential effectiveness of cooperative, competitive and individualistic classroom interaction patterns on students' chemical problem-solving skills. The Nigerian Teacher Today, I (2), 121-129

Omofonmwan, S.L and Osa-Edoh, G. L (2008). The challenges of environmental problems in Nigeria. Ekpoma: Department of Geography and Planning and Educational Foundation Ambrose Ali University, Kaunla-Ray. 23(1): 53-55.

Russell, W. B. \& Watersm S. (2010). Instructional Methods for Teaching Social Studies: A Survey of What Middle School Students Like and Dislike about Social Studies Instruction. Journal for the Liberal Arts and Sciences 14(2).

Salami, E.F.K. (1996). Introduction to the teaching of Social Studies. Ondo: Unpublish SOS 335 Material, Adeyemi College of Education Ondo.

Steffe, L. P., and Gale, J., (Eds.) (1995). Constructivism in education. Hillsdale, NJ: Erlbaum.Sullo (2012) 
Tam, M., (2000). Constructivism, instructional design, and technology: implications for transforming distance learning. Educational Technology and Society 3(2) 2000 ISSN 1436-4522 http://www.ifets.info/journals/3_2/tam.html

Terenzini, P. T., Cabrera, A. F. Carol L. Colbeck, C. L., Parente, J. M. \& Bjorklund, S. A. (2001).Collaborative learning vs. lecture/discussion: students' reported learning gains. Journal of Engineering Education 123-130.

Wilke, R. J., Peyton, R., B.\& Hungerford, H. R. (1987). Strategies for the training of teachers in environmental education. Unesco-UNEP International Environmental Education Programme: Environmental Education Series 25.

Yusuf, AbdulRaheem (n. d) Effect of Cooperative Instructional Strategy on Students' Performance in Social Studies 
